ORIGINAL ARTICLE

\title{
Examining the impact of mindfulness and self-compassion on the relationship between mental health and resiliency
}

\author{
Fajar Rizal ${ }^{A, B, C, D, E, F}$, Helen Egan $\mathbb{D}^{E}$, Amy Cook ${ }^{E}$, Rebecca Keyte ${ }^{E}$, Michail Mantzios $\mathbb{( D D}^{A, C, D, E, F}$ \\ Birmingham City University, Birmingham, United Kingdom
}

\section{BACKGROUND}

Mechanisms for improving resiliency, and the potential benefits of doing so, are not well evidenced and understood. This research explored the relationship between mental health and resiliency, to broaden the perspectives of influences on resiliency by controlling for mindfulness and self-compassion.

\section{PARTICIPANTS AND PROCEDURE}

One questionnaire comprised four pre-developed questions, examining mental health (i.e., depression, anxiety and stress), resilience, mindfulness and self-compassion. Participants $(N=551)$ were recruited from the general public across the West and East Midlands of England.

\section{RESULTS}

The results showed that poor mental health was related negatively to resilience. Furthermore, the negative relationship of resiliency with mental health was mediated when controlling for mindfulness and self-compassion.

\section{CONCLUSIONS}

Mindfulness and compassion-based interventions have the potential to develop resiliency by influencing their relationship with health. Future directions are discussed.

\section{KEY WORDS}

mental health; resilience; mindfulness; self-compassion

Corresponding Author - Michail Mantzios, Ph.D., Birmingham City University, The Curzon Building Room C307,

B4 7BD Birmingham, United Kingdom, e-mail: michael.mantzios@bcu.ac.uk

Authors' Contribution - A: Study design · B: Data collection · C: Statistical analysis · D: Data interpretation ·

E: Manuscript preparation · F: Literature search · G: Funds collection

to Cite this ARTICLE - Rizal, F., Egan, H., Cook, A., Keyte, R., \& Mantzios, M. (2020). Examining the impact of mindfulness

and self-compassion on the relationship between mental health and resiliency. Current Issues in Personality Psychology, $8(4), 279-288$ 


\section{BACKGROUND}

Research has shown that stressful environments can increase the chances of individuals developing decreased job satisfaction, depression and other problems including physical injury, anxiety or other mood disorders (Greenberg, Jones, Jones, Fear, \& Wessely, 2011). This can harm an individual's cognitive functioning and may contribute to poorer behaviours (e.g., substance abuse, family dysfunction, marital problems, social isolation, and in extreme cases, suicide or suicide attempts; Iversen et al., 2008). Indeed, in such cases being resilient is key to overcoming barriers to ill mental health and improving overall wellbeing. Early definitions for resilience first arise in physics and engineering, where it defines the ability for a material to "bounce back" to its original form when unloading the application of extensive energy without creating a permanent distortion (Wied, Oehmen, \& Welo, 2019). This definition also has application to psychology regarding to the ability to "bounce back" when individuals are faced with disappointments, defeats, and failures, and instead of wallowing or letting things keep them down, individuals tend to get back up and continue on with their lives (Smith, Tooley, Christopher, \& Kay, 2010). Some research exists between ill mental health and resiliency, but has focused on specific populations such as spinal injury, health professionals and students (e.g., Hayter \& Dorstyn, 2014; Kemper, Mo, \& Khayat, 2015; McArthur et al., 2017; Pidgeon \& Keye, 2014). Both self-compassion and mindfulness are important concepts for resiliency, with little being known about these relationships through general population studies in the United Kingdom.

According to Ruiz-Casares, Guzder, Rousseau, and Kirmayer (2014), resilience can be described both as a trait and a dynamic process of development, involving social interactions and compensatory behaviours over the lifespan. Eggerman and Panter-Brick (2010) carried out a study on health-related issues and resiliency in war-affected areas. Their research aimed to identify how an individual makes sense of adversity and why they show resilience in a high-risk environment. They reported that these individuals possess resilience through the belief that adversity can be overcome by adhering to cultural values (e.g., religion, family unity, morals, and daily perseverance). Research by Shrivastava, De Sousa, Sonavane, and Shah (2016) led to hypothesising and verifying that an individual's resilience may be linked between positive cognition and the outcome of mental wellbeing.

There is a general consensus that mental health illnesses such as depression, anxiety, and stress impact upon individuals (e.g., Bolton, 2009). Understanding mental health issues efficiently can enable an individual to cope with adversity, reach their full potential and achieve optimal levels of wellbeing.
Research has consistently demonstrated that individuals with mental health issues experience an increase of occupational absenteeism, with a resulting negative impact on productivity and profits (Bender \& Farvolden, 2008; Rajgopal, 2010). Depression is a common and debilitating mental health disorder that negatively affects how individuals feel, think and behave. This can further cause feelings of sadness and/or a loss of interest in activities that were once enjoyed, leading to a variety of emotional and physical problems and a decrease in an individuals' ability to function at work and/or at home (APA, 2013; McLaughlin, 2011).

According to Bittner et al. (2004), anxiety is an emotion characterized by feelings of tension, worried thoughts and physical changes (such as increased blood pressure). People with anxiety disorders often have recurring intrusive thoughts or concerns that can result in avoiding certain situations out of worry and may have physical symptoms (e.g., sweating, trembling, dizziness or rapid heartbeat) (APA, 2013; Bystritsky, Khalsa, Cameron, \& Schiffman, 2013). Research has also identified that anxiety can result in behaviours such as worry and impulsivity. Characteristics such as impulse control (i.e., gambling, self-harming), mood disorders and anxiety disorders can be the resulting effects of altering an individual's behaviour (Schaefer, Esposito-Smythers, \& Riskind, 2012; Mantzios, 2014; Jakuszkowiak-Wojten, Landowski, Wiglusz, \& Cubała, 2015).

Similarly, stress is another significant contributor that can negatively affect an individual's well-being. People have different coping abilities to deal with demands and experiences, which may be deemed to be more stressful to some. For instance, deadlines, workrelated pressure (such as upholding good service) and complex problem solving can cause higher levels of anxiety and stress amongst individuals (Brand, Nakkas, \& Annen, 2016). Overall, the literature indictates that mental health issues can contribute negatively in several ways throughout the lifespan, and public health incentives are a long way from influencing the current way mental health is identified and treated (see Mantzios, 2020; Mantzios, Egan, \& Cook, 2019a, b). Problems such as increased absenteeism, impulsive behaviours, emotional and physical issues at work and home, as outcomes of mental illness, highlight the need for interventions to provide resolutions for poor mental health, and often interventions are proposed though increasing resiliency.

Research has considered such possible tools to enhance mental health through resiliency to be mindfulness and self-compassion. The trait of mindfulness has been described as fostering greater attention to and awareness of present-moment experiences (Creswell, 2017). Mindfulness assists in improving mental health, where research showed that higher levels of mindfulness assist with mental illness (Baer, Lykins, 
\& Peters, 2012). Kabat-Zinn (2003) described the practice of mindfulness as being attentive to the present moment and non-judgemental with oneself. Past research, indeed, demonstrated that individuals with higher scores in mindfulness are more likely to experience lower levels of depression and anxiety, further suggesting that individuals can successfully regulate emotions and positive cognition, as mindfulness can be a proactive tool for fostering health and subjective wellbeing for individuals (Allen, Henderson, Mancini, \& French, 2017; Dutt, Keyte, Egan, Hussain, \& Mantzios, 2019; Gu, Strauss, Bond, \& Cavanagh, 2015; Ilies, Egan, \& Mantzios, 2019; Mantzios, Wilson, Linnell, \& Morris, 2014). Conversely, being less mindful can induce behavioural symptoms such as low motivation, which in turn may lead to depression or anxiety (Keng, Smoski, \& Robins, 2011). Stress and anxiety may make an individual move away from the present moment and result in repetitive patterns of negative thinking, which may develop to a more severe form of mental illness (Mantzios \& Wilson, 2013). The nature of an individual's day-to-day life can be typically overwhelming, thus extinguishing any ability to be mindful, but reinstating mindful living through practice may form a method of optimal wellbeing.

Similarly, Neff (2003) defines self-compassion as an experience of one's own suffering such as perceived inadequacy, failures or general suffering, through three main components including: self-kindness (being sympathetic to oneself when experiencing pain and personal failings, rather than ignoring them or hurting oneself with self-criticism), common humanity (recognising that failures and sufferings are part of a shared common human experience) and mindfulness (observing negative thoughts and emotions as they are without trying to suppress or deny them). Moreover, self-compassion associates negatively with self-criticism, which has been found to positively relate to symptoms such as depression and anxiety, and impact life satisfaction and social connectedness (e.g., LoParo, Mack, Patterson, Negi, \& Kaslow, 2018). To enhance mental health and resiliency, individuals need to identify failures and realise that poor mental health may need a compassionate reflection that is balanced between physical and mental expressions of self-care (Ali, Wong, Egan, Cook, \& Mantzios, 2017; Egan et al., 2019; Egan \& Mantzios, 2018; Mantzios \& Egan, 2017; Mantzios \& Giannou, 2018). Leary, Tate, Adams, Batts-Allen, and Hancock (2007) stated that self-compassion is the ability to be compassionate to oneself, and without this ability, individuals will lack the skills to tolerate stressful environments (such as work or family stressors). On the other hand, mindfulness can be a tool to help individuals with and without personal self-reflections of suffering to understand, tolerate, and deal with their emotions in a healthy way (Donald, Atkins, Parker, Christie, \& Ryan, 2016).
Recent research indicated that higher scores of self-compassion reduce the association of depressive symptoms (Zhang et al., 2019) and strong positive relationships to an individual's cognitive and psychological well-being (Zessin, Dickhäuser, \& Garbade, 2015). Along with an improved quality of life for individuals, self-compassion has a direct effect on health-related factors, as well as an indirect relationship through resilience (Roulston, Montgomery, Campbell, \& Davidson, 2017; Nery-Hurwit, Yun, \& Ebbeck, 2018). Therefore, self-compassion is a vital aspect when exploring the benefits of mindfulness for mental health and resiliency by motivating individuals to physically, mentally or emotionally support themselves (Limebury \& Shea, 2015). These findings appear to explain how an individual can better deal with stressors, where self-compassion can help to identify and accept negative aspects of one's life, and improve an individual's self-esteem (Kim \& Ko, 2018; Mongrain, Chin, \& Shapira, 2010).

The ever-changing environment experienced by individuals during everyday tasks is frequentlhy adverse and stressful, and the importance of placing interventions at the forefront to enhance resiliency and improve wellbeing is imperative. Being mindful and compassionate with oneself can have a positive impact on an individual's wellbeing, physically and mentally (Horan \& Taylor, 2018). Thus, incorporating mindfulness and compassion-based interventions may mitigate long-term mental health issues by understanding the individual's ability to adapt to the environment (Wamsler, 2018). There is, however, a need for further evidence before suggesting interventions.

This work builds on the need to identify the intangible nature of resiliency. The purpose of this study was to examine whether mindfulness and selfcompassion are mechanisms through which mental health (i.e., depression, anxiety and stress) influences resiliency. Hence, using mindfulness and self-compassion as potential mediating factors to mediate the relationship between resiliency and mental health was explored in the present research. The present study hypothesised that depression, anxiety and stress relate negatively to resilience, and such a relationship is mediated through self-compassion and mindfulness.

\section{PARTICIPANTS AND PROCEDURE}

\section{PARTICIPANTS}

Five-hundred and fifty-one people responded to the call to take part in this research from the general community of West and East Midlands in England. Prior to analysis, the data were screened for outliers, normality and missing data. After deleting a sample with no or excessively missing data, 367 participants 
remained (121 males, 246 females) with a mean age of $24.32(S D=7.01)$. Participants were recruited through snowball sampling (Faugier \& Sargeant, 1997) via online forums and social media group pages. Recruitment of participants was voluntary and did not involve any incentives. Cohen's (1992) guidelines suggested that to achieve a medium effect size a minimum of 300 participants was required (Cohen, 1992).

\section{MEASURES}

Demographics questionnaire. Participants' background information such as gender, age, and ethnicity, as well as previous and current diagnoses of ill mental health, was explored as a method of analysing the results on the basis of recruiting a healthy community population.

Depression, Anxiety, and Stress Scale (DASS; Lovibond \& Lovibond, 1995). DASS consists of 21 items, designed to measure related negative emotional states. The depression scale assesses devaluation of life, self-deprecation and lack of interest or involvement. The anxiety scale assesses situational anxiety and subjective experience of anxious effects. The stress scale assesses difficulty in relaxing, nervous arousal, being easily upset or agitated, and impatient behaviours. Example items include the following: "I found it hard to wind down" measured stress; "I was aware of dryness of my mouth" measured anxiety and items such as "I couldn't seem to experience any positive feeling at all" measured depression. The calculation scores were measured on a 4-point Likert scale which ranged from 0 (did not apply to me at all) to 3 (applied to me very much or most of the time). The present study produced a Cronbach's $\alpha$ of .86 .

Self-Compassion Scale (SCS; Neff's, 2003). SCS consists of 26 items designed to measure 6 bidirectional elements of self-compassion including self-kindness (five items) vs. self-judgment (five items); common humanity (four items) vs. isolation (four items); mindfulness (four items) vs. over-identification (four items). Example items include the following: "I try to be loving towards myself when I'm feeling emotional pain" measures self-kindness; "I'm disapproving and judgmental about my own flaws and inadequacies" measures self-judgment; "When things are going badly for me, I see the difficulties as part of life that everyone goes through" measures common humanity. The calculation scores were measured on a 5-point Likert scale which ranged from 1 (almost never) to 5 (almost always). Negative subscale items including self-judgment, isolation, and over-identification were reverse scored (i.e., $1=5,2=4,3=3,4=2$, and $5=1$ ). The present study produced a Cronbach's $\alpha$ of .77 .

Five Facet Mindful Questionnaire (FFMQ; Bohlmeijer, ten Klooster, Fledderus, Veehof, \& Baer, 2011). The questionnaire tested five facets including non- reactivity to inner experiences, observing, act awareness, describing and non-judging of inner experiences. Example items include: "I'm good at finding the words to describe my feeling" and "I watch my feelings without getting carried away by them", which measured non-reactivity and describe mindfulness, while items such as "I find myself doing things without paying attention" and "I disapprove of myself for illogical ideas" measured act awareness and nonjudgemental components of mindfulness. The calculation scores consisted of responses measured on a 5-point Likert scale which ranged from 1 (never or very rarely true) to 5 (very often or always true). The present study produced a Cronbach's $\alpha$ of .70.

10-item Connor-Davidson Resilience Scale (CDRISC-10; Campbell-Sills \& Stein, 2007). CD-RISC-10 illustrated Connor and Davidson's (2003) 25-item CD-RISC that was based on Connor and Davidson's operational definition of resilience, which is the ability to thrive in the face of adversity. However, the original scale was rejected due to the extensive administration timescale. Example items include: "Able to adapt to change" and "Can deal with whatever comes". The calculation scores consisted of responses measured on a 5-point Likert scale which ranged from 0 (never) to 4 (almost always). The present study produced a Cronbach's $\alpha$ of .87 .

\section{PROCEDURE}

Ethical approval was obtained from the ethical board within the university and this study followed ethical practices following the British Psychological Society. Participants were recruited using a hyperlink posted in forums and social media group pages. The general information sheet, consent form, and demographics were administered concurrently to all participants through Qualtrics. The participant signed the consent form by creating a unique candidate number which indicated anonymity and their voluntary participation. Participants began the research by answering the DASS, followed by FFMQ, and then SCS questionnaire, concluding with the CD-RISC- 10 . The debrief form indicated the end of the research.

\section{STATISTICAL ANALYSIS}

This study used a Pearson's bivariate correlation to explore the relationships. Next, the relationship between wellbeing (through the overall score of the DASS) and resilience was explored by investigating the potential mediation of this relationship through mindfulness and self-compassion. The results were followed up by exploring mediations to examine the relationship between depression, anxiety and stress to resilience, and the potential mediation of this 
relationship through mindfulness and self-compassion. Mediation analyses were carried out using the PROCESS macro (Hayes, 2015) in SPSS version 24, with 5,000 bootstrapped samples and bias corrected 95\% confidence intervals. Mediation analyses were run to assess the impact of mindfulness and selfcompassion as mediators.

Following previous research further analysis on gender and age was conducted to identify statistically significant differences in emotion (e.g., Brummer, Stopa, \& Bucks, 2013; Soysa \& Wilcomb, 2015), self-compassion (e.g., Neff \& Pommier, 2013; Yarnell et al., 2015), mindfulness (e.g., Lilja et al., 2011; Mahoney, Segal, \& Coolidge, 2015), and resilience (e.g., Friborg, Hjemdal, Rosenvinge, \& Martinussen, 2003), but the results did not yield any significance.

\section{RESULTS}

Initially, a bivariate correlation was conducted, and the findings suggested a positive correlation between mindfulness, self-compassion and resiliency traits. These traits were negatively associated with stress, anxiety and depression (see Table 1).
The first mediational model predicted resiliency. The model analysed resiliency as the dependant variable, DASS as the independent variable, and mindfulness and self-compassion as potential mediators. Firstly, DASS predicting resiliency showed a significant direct effect $(F(1,365)=65.18, p<.001$, $\left.R^{2}=.20\right)$. Second, DASS predicting mindfulness showed a significant direct effect $(F(1,365)=37.80$, $\left.p<.001, R^{2}=.10\right)$ as well as self-compassion $\left(F(1,365)=144.02, p<.001, R^{2}=.30\right)$. When DASS total, mindfulness and self-compassion were analysed to predict resiliency, the results indicated a significant direct effect $\left(F(1,365)=70.98, p<.001, R^{2}=.38\right)$ (see Table 2).

The second mediation model predicted resiliency when controlling for depression. Firstly, depression predicting resiliency showed a significant direct effect $\left(F(1,365)=62.04, p<.001, R^{2}=.18\right)$. Second, depression predicting mindfulness showed a significant direct effect $\left(F(1,365)=26.09, p<.001, R^{2}=.07\right)$ as well as self-compassion $(F(1,365)=136.81$, $\left.p<.001, R^{2}=.29\right)$. When depression, mindfulness and self-compassion were analysed to predict resiliency, the results indicated a significant direct effect $\left(F(1,365)=66.23, p<.001, R^{2}=.37\right)($ see Table 3$)$.

Table 1

Pearson's bivariate correlation summary for variables of interest

\begin{tabular}{|c|c|c|c|c|c|c|c|c|c|}
\hline Variable & CD-RISC-10 & DASS Total & Depression & Anxiety & Stress & FFMQ & SCS & $M$ & $S D$ \\
\hline CD-RISC-10 & - & & & & & & & 36.19 & 7.46 \\
\hline DASS Total & $-.45^{* *}$ & - & & & & & & 42.25 & 12.85 \\
\hline Depression & $-.43^{* *}$ & $.92^{* *}$ & - & & & & & 13.81 & 5.65 \\
\hline Anxiety & $-.42^{* *}$ & $.90^{* *}$ & $.72^{* *}$ & - & & & & 13.06 & 5.17 \\
\hline Stress & $-.37^{* *}$ & $.93^{* *}$ & $.72^{* *}$ & $.76^{* *}$ & - & & & 15.37 & 5.37 \\
\hline FFMQ & $.15^{* *}$ & $-.33^{* *}$ & $-.28^{* *}$ & $-.31^{* *}$ & $-.30^{* *}$ & - & & 2.74 & 9.69 \\
\hline SCS & $.53^{* *}$ & $-.55^{* *}$ & $-.54^{* *}$ & $-.43^{* *}$ & $-.55^{* *}$ & -.06 & - & 75.58 & 16.91 \\
\hline
\end{tabular}

Note. ${ }^{*} p<.05,{ }^{* *} p<.01,{ }^{* *} p<.001 ;$ FFMQ - Five Facet Mindfulness Questionnaire, SCS - Self-Compassion Scale, DASS - Depression, Anxiety, and Stress Scale, CD-RISC-10 - 10-item Connor-Davidson Resilience Scale.

Table 2

Mediation of the effect of DASS on resiliency through mindfulness and self-compassion

\begin{tabular}{|c|c|c|c|c|c|}
\hline \multirow[t]{3}{*}{ DASS Total } & \multicolumn{5}{|c|}{ Resilience } \\
\hline & \multirow[t]{2}{*}{$\beta$} & \multirow[t]{2}{*}{$t$} & \multirow[t]{2}{*}{$p$} & \multicolumn{2}{|c|}{$95 \% \mathrm{Cl}$} \\
\hline & & & & Lower & Upper \\
\hline Total $(c)$ & -.22 & -8.07 & $<.001$ & -.28 & -.17 \\
\hline Direct $\left(c^{1}\right)$ & .16 & -5.25 & $<.001$ & -.23 & -.10 \\
\hline Mindfulness & .21 & 5.48 & $<.001$ & .14 & .27 \\
\hline Self-Compassion & .16 & 7.53 & $<.001$ & -.73 & -.53 \\
\hline
\end{tabular}

Note. Total $(c)=$ Direct $\left(c^{1}\right)+$ Indirect Mindfulness + Indirect Self-Compassion; 95\% confidence interval with 5,000 bootstrap samples. 
Table 3

Mediation of the effect of depression on resiliency through mindfulness and self-compassion

\begin{tabular}{lccccc}
\hline Depression & \multicolumn{5}{c}{ Resilience } \\
\cline { 2 - 6 } & $\beta$ & $t$ & $p$ & \multicolumn{2}{c}{$95 \% \mathrm{Cl}$} \\
\cline { 3 - 6 } & & & & Lower & Upper \\
\hline Total $(c)$ & -.56 & -7.87 & -.001 & -.70 & -.42 \\
Direct $\left(c^{1}\right)$ & -.37 & -4.89 & $<.001$ & -.52 & -.22 \\
Mindfulness & .19 & 4.93 & $<.001$ & .12 & .27 \\
Self-Compassion & .18 & 8.35 & $<.001$ & .13 & .22 \\
\hline
\end{tabular}

Note. Total $(c)=$ Direct $\left(c^{T}\right)+$ Indirect Mindfulness + Indirect Self-Compassion; 95\% confidence interval with 5,000 bootstrap samples.

Table 4

Mediation of the effect of stress on resiliency through mindfulness and self-compassion

\begin{tabular}{lccccc}
\hline Stress & \multicolumn{3}{c}{ Resilience } \\
\cline { 2 - 6 } & $\beta$ & $t$ & $p$ & \multicolumn{2}{c}{$95 \% \mathrm{Cl}$} \\
\cline { 3 - 6 } & & & & Lower & Upper \\
\hline Total $(c)$ & -.52 & -6.63 & $<.001$ & -.67 & -.37 \\
Direct $\left(c^{1}\right)$ & -.28 & -3.35 & $<.001$ & -.44 & -.12 \\
Mindfulness & .18 & 4.58 & $<.001$ & .10 & .26 \\
Self-Compassion & .19 & 8.88 & $<.001$ & .15 & .24 \\
\hline
\end{tabular}

Note. Total $(c)=$ Direct $\left(c^{1}\right)+$ Indirect Mindfulness + Indirect Self-Compassion; 95\% confidence interval with 5,000 bootstrap samples.

Table 5

Mediation of the effect of anxiety on resiliency through mindfulness and self-compassion

\begin{tabular}{lccccc}
\hline Anxiety & \multicolumn{3}{c}{ Resilience } & \\
\cline { 2 - 6 } & $\beta$ & $t$ & $p$ & \multicolumn{2}{c}{$95 \% \mathrm{Cl}$} \\
\cline { 3 - 6 } & & & & Lower & Upper \\
\hline Total $(c)$ & -.61 & -7.57 & $<.001$ & -.77 & -.45 \\
Direct $\left(c^{1}\right)$ & -.49 & -5.92 & $<.001$ & -.65 & -.33 \\
Mindfulness & .21 & 5.74 & $<.001$ & .14 & .29 \\
Self-Compassion & .18 & 9.37 & $<.001$ & .14 & .22 \\
\hline
\end{tabular}

Note. Total $(c)=$ Direct $\left(c^{1}\right)+$ Indirect Mindfulness + Indirect Self-Compassion; $95 \%$ confidence interval with 5,000 bootstrap samples.

The third mediation model predicts resiliency when controlling for stress. Firstly, stress predicting resiliency showed a significant direct effect $\left(F(1,365)=44.00, p<.001, R^{2}=.14\right)$. Second, stress predicting mindfulness showed a significant direct effect $\left(F(1,365)=32.07, p<.001, R^{2}=.08\right)$ as well as self-compassion $\left(F(1,365)=134.48, p<.001, R^{2}=.30\right)$. When stress, mindfulness and self-compassion were analysed to predict resiliency, the results indicated a significant direct effect $(F(1,365)=60.88, p<.001$, $R^{2}=.34$ ) (see Table 4 ).
The final mediation model predicts resiliency when controlling for anxiety. Firstly, stress predicting resiliency showed a significant direct effect $\left(F(1,365)=57.35, p<.001, R^{2}=.17\right)$. Second, anxiety predicting mindfulness showed a significant direct effect $\left(F(1,365)=34.78, p<.001, R^{2}=.09\right)$ as well as self-compassion $\left(F(1,365)=82.62, p<.001, R^{2}=.17\right)$. When stress, mindfulness and self-compassion were analysed to predict resiliency, the results indicated a significant direct effect $(F(1,365)=78.87, p<.001$, $\left.R^{2}=.40\right)$ (see Table 5). 


\section{DISCUSSION}

The present study aimed to identify the relationship between mental health and resiliency and investigated whether or not mindfulness and self-compassion could mediate such relationships by controlling for their influence. Firstly, correlation analysis indicated that mental health correlated negatively with resiliency. This suggests that as mental health issues decreased, resiliency increased and vice versa. When the total DASS score was used, self-compassion and mindfulness mediated the relationship between mental health and resiliency. Subscales also proposed that mindfulness and self-compassion were equally effective in mediating the relationship. The findings were consistent with previous research (see Mantzios, 2014; Färber \& Rosendahl, 2018) suggesting that poor mental health can affect resiliency, and therefore overall wellbeing.

The present findings build on existing evidence of other research that looked into the benefit of mindfulness and self-compassion (e.g., Baer et al., 2012; Brewer, 2014; Meland et al., 2015). It is fair to assume that identifying these psychological traits (i.e., mindfulness and self-compassion) as potentially enhancing mental health and resiliency may mediate further health behaviours (e.g., smoking, addiction and eating impulsively) (Egan, Mantzios, \& Jackson, 2017; Egan \& Mantzios, 2018). In addition, the findings supported research such as that by Mantzios (2014), who reported that mindfulness and self-compassion are useful strategies in dealing with behaviours such as worry and impulsivity, which are associated with anxiety and stress.

As discussed earlier, when the DASS subscale and total scores were analysed, self-compassion was a better mediator when compared to mindfulness. Such a finding could be explained in light of an individual's experience to pay attention to themselves and have the cognitive ability to consider emotions focused on care-giving, kindness and loving oneself and to one's well-being (Neff, 2003; Mantzios \& Egan, 2017). This research further supports studies on the benefits of self-compassion and well-being. It has been identified that self-compassion can provide emotional benefits including a shift in perspectives, creativity and better overall health (Graham, 2016), which directly affect the outcome of resiliency in individuals in any given situation. Therefore, it is fair to assume that the perspective shift can improve resilience (even in adverse environments) and improve productivity (e.g., Mantzios \& Wilson, 2015).

There were a few notable limitations in the present research. First, the design of the research was crosssectional; therefore, no firm conclusion could be drawn on the relational design between constructs. Findings for the use of mindfulness and compassionbased interventions need to be investigated further in experimental settings and/or longitudinal designs, to demonstrate credible changes in practice. Second, missing data may be another limitation. Missing data may suggest that only motivated participants filled in the questionnaire, which may have implications for generalising the findings further. Despite these limitations, the results of this study may provide an initial insight into the relative relationships between mindfulness and self-compassion among an individual's well-being and resilience and inform future research and practices. Third, the questionnaire was not randomised when presented to each participant so there was a potential exposure to order effect. Fourth, using the CD-RISC-10 scale suggests that the majority of the sample were resilient, which may limit the generalisability of the data. Fifth, the attrition rate of the sample was high compared to other research, though normative data did not indicate any significant differences.

In conclusion, the current study suggests that mindfulness and self-compassion can positively influence the relationship between mental health and resiliency. These findings also provide evidence that mindfulness and self-compassion may be a useful intervention in supporting mental health. Further research is needed to corroborate these results and build controlled empirical studies that test the efficacy of mindfulness and compassion-based intervention for shifting an individual's perspective to be better equipped to anticipate and cope with everyday stressors

\section{REFERENCES}

Ali, Z., Wong, K., Egan, H., Cook, A., \& Mantzios, M. (2017). All you can eat buffets, obesity, mindfulness, and mindful eating: an exploratory investigation. Journal of Psychology and Psychiatry, 1, 1-5. https://doi.org/10. 15761/JPP.1000101

Allen, T., Henderson, T., Mancini, V., \& French, K. (2017). Mindfulness and meditation practice as moderators of the relationship between age and subjective wellbeing among working adults. Mindfulness, 8, 10551063. https://doi.org/10.1007/s12671-017-0681-6

APA (2013). Diagnostic and statistical manual of mental disorders - DSM-5. Washington, DC: APA Publishing.

Baer, R., Lykins, E., \& Peters, J. (2012): Mindfulness and self-compassion as predictors of psychological wellbeing in long-term meditators and matched nonmeditators, The Journal of Positive Psychology, 7, 230-238. https://doi.org/10.1080/17439760.2012.6 74548

Bender, A., \& Farvolden, P. (2008). Depression and the workplace: a progress report. Current Psychiatry Reports, 10, 73-79. https://doi.org/10.1007/s11920008-0013-6 
Bittner, A., Goodwin, R., Wittchen, H., Beesdo, K., Höfler, M., \& Lieb, R. (2004). What characteristics of primary anxiety disorders predict subsequent major depressive disorder? The Journal of Clinical Psychiatry, 65, 618-626. https://doi.org/10.4088/jcp. v65n0505

Bohlmeijer, E., ten Klooster, P., Fledderus, M., Veehof, M., \& Baer, R. (2011). Psychometric properties of the Five Facet Mindfulness Questionnaire in Depressed Adults and development of a short form. Assessment, 18, 308-320. https://doi.org/ $10.1177 / 1073191111408231$

Bolton, D. (2009). What is mental disorder? Psychiatry, 8, 468-470. https://doi.org/10.1016/j.mppsy.2009. 09.002

Brand, S., Nakkas, C., \& Annen, H. (2016). Psychological distress and coping in military cadre candidates. Neuropsychiatric Disease and Treatment, 12, 2237-2243. https://doi.org/10.2147/ndt.s 113220

Brewer, J. (2014). Mindfulness in the military. American Journal of Psychiatry, 171, 803-806. https://doi. org/10.1176/appi.ajp.2014.14040501

Brummer, L., Stopa, L., \& Bucks, R. (2013). The influence of age on emotion regulation strategies and psychological distress. Behavioural and Cognitive Psychotherapy, 42, 668-681. https://doi. org/10.1017/S1352465813000453

Bystritsky, A., Khalsa, S., Cameron, M., \& Schiffman, J. (2013). Current diagnosis and treatment of anxiety disorders. Pharmacy and Therapeutics, 38, 30-57.

Campbell-Sills, L., \& Stein, M. B. (2007). Psychometric analysis and refinement of the Connor-Davidson Resilience Scale (CD-RISC): Validation of a 10-item measure of resilience. Journal of Traumatic Stress, 20, 1019-1028. https://doi.org/10.1002/jts.20271

Cohen, J. (1992). Statistical power analysis. Current Directions in Psychological Science, 1, 98-101. https://doi.org/10.1111/1467-8721.ep10768783

Connor, K. M., \& Davidson, J. R. T. (2003). Development of a new resilience scale: The Connor-Davidson Resilience Scale (CD-RISC). Depression and Anxiety, 18, 76-82. https://doi.org/10.1002/da.10113

Creswell, J. (2017). Mindfulness interventions. Annual Review of Psychology, 68, 491-516. https://doi. org/10.1146/annurev-psych-042716-051139

Donald, J., Atkins, P., Parker, P., Christie, A., \& Ryan, R. (2016). Daily stress and the benefits of mindfulness: Examining the daily and longitudinal relations between present-moment awareness and stress responses. Journal of Research in Personality, 65, 30-37. https://doi.org/10.1016/j.jrp.2016.09.002

Dutt, S., Keyte, R., Egan, H., Hussain, M., \& Mantzios, M. (2019). Healthy and unhealthy eating amongst stressed students: Considering the influence of mindfulness on eating choices and consumption. Health Psychology Report, 7, 113-120. https://doi.org/10.5114/hpr.2019.77913
Egan, H., Keyte, R., McGowan, K., Peters, L., Lemon, N., Parsons, S., Meadows, S., Fardy, T., Singh., P., \& Mantzios, M. (2019). 'You before me': a qualitative study of health care professionals' and students' understanding and experiences of compassion in the workplace, self-compassion, self-care and health behaviours. Health Professions Education, 5, 225-236. https://doi.org/10.1016/j.hpe.2018. 07.002

Egan, H., \& Mantzios, M. (2018). A qualitative exploration of self-kindness and "treating oneself" in contexts of eating, weight regulation and other health behaviors: Implications for mindfulnessbased eating programs. Frontiers in Psychology, 9, 880. https://doi.org/10.3389/fpsyg.2018.00880

Egan, H., Mantzios, M., \& Jackson, C. (2017). Health practitioners and the directive towards compassionate healthcare in the UK: Exploring the need to educate health practitioners on how to be selfcompassionate and mindful alongside mandating compassion towards patients. Health Professions Education, 3, 61-63. https://doi.org/10.1016/j. hpe.2016.09.002

Eggerman, M., \& Panter-Brick, C. (2010). Suffering, hope, and entrapment: Resilience and cultural values in Afghanistan. Social Science \& Medicine, 71, 7183. https://doi.org/10.1016/j.socscimed.2010.03.023

Färber, F., \& Rosendahl, J. (2018). The association between resilience and mental health in the somatically ill. Deutsches Aerzteblatt Online, 115, 621-627. https://doi.org/10.3238/arztebl.2018.0621

Faugier, J., \& Sargeant, M. (1997). Sampling hard to reach populations. Journal of Advanced Nursing, 26, 790-797. https://doi.org/10.1046/j.1365-2648.1997. 00371.x

Friborg, O., Hjemdal, O., Rosenvinge, J. H., \& Martinussen, M. (2003). A new rating scale for adult resilience: What are the central protective resources behind healthy adjustment? International Journal of Methods in Psychiatric Research, 12, 65-76. https://doi.org/10.1002/mpr.143

Graham, L. (2016). Mindfulness, self-compassion and resilience. Retrieved from https://lindagraham-mft. net/mindfulness-self-compassion-and-resilience/

Greenberg, N., Jones, E., Jones, N., Fear, N., \& Wessely, S. (2011). The injured mind in the UK Armed Forces. Philosophical Transactions of The Royal Society B: Biological Sciences, 366, 261-267. https:// doi.org/10.1098/rstb.2010.0210

Gu, J., Strauss, C., Bond, R., \& Cavanagh, K. (2015). How do mindfulness-based cognitive therapy and mindfulness-based stress reduction improve mental health and wellbeing? A systematic review and meta-analysis of mediation studies. Clinical Psychology Review, 37, 1-12. https://doi.org/10.1016/j. cpr.2015.01.006

Hayes, A. F. (2015). An index and test of linear moderated mediation. Multivariate Behavioral Research, 
50, 1-22. https://doi.org/10.1080/00273171.2014.96 2683

Hayter, M. R., \& Dorstyn, D. S. (2014). Resilience, self-esteem and self-compassion in adults with spina bifida. Spinal Cord, 52, 167-171. https://doi. org/10.1038/sc.2013.152

Horan, K., \& Taylor, M. (2018). Mindfulness and selfcompassion as tools in health behavior change: An evaluation of a workplace intervention pilot study. Journal of Contextual Behavioral Science, 8, 8-16. https://doi.org/10.1016/j.jcbs.2018.02.003

Ilies, I. A., Egan, H., \& Mantzios, M. (2019). Comparing state anxiety and mindfulness between mindfulness and loving-kindness meditation whilst controlling for the effect of altruism and boredom. Current Issues in Personality Psychology, 7, 109-119. https://doi.org/10.5114/cipp.2019.85412

Iversen, A., Fear, N., Ehlers, A., Hacker Hughes, J., Hull, L., Earnshaw, M., Greenberg, N., Rona, R., Wessely, S., \& Hotopf, M. (2008). Risk factors for post-traumatic stress disorder among UK Armed Forces personnel. Psychological Medicine, 38, 511522. https://doi.org/10.1017/s0033291708002778

Jakuszkowiak-Wojten, K., Landowski, J., Wiglusz, M., \& Cubała, W. (2015). Impulsivity in Anxiety Disorders. A critical review. Psychiatria Danubina, 27, S452-S455.

Kabat-Zinn, J. (2003). Mindfulness-based interventions in context: Past, present and future. Clinical Psychology: Science and Practice, 10, 144-156. https:// doi.org/10.1093/clipsy.bpg016

Kemper, K. J., Mo, X., \& Khayat, R. (2015). Are mindfulness and self-compassion associated with sleep and resilience in health professionals? The Journal of Alternative and Complementary Medicine, 21, 496-503. https://doi.org/10.1089/acm.2014.0281

Keng, S., Smoski, M., \& Robins, C. (2011). Effects of mindfulness on psychological health: a review of empirical studies. Clinical Psychology Review, 31, 1041-1056. https://doi.org/10.1016/j.cpr.2011. 04.006

Kim, C., \& Ko, H. (2018). The impact of self-compassion on mental health, sleep, quality of life and life satisfaction among older adults. Geriatric Nursing, 39, 623-628. https://doi.org/10.1016/j.gerinurse.2018.06.005

Leary, M., Tate, E., Adams, C., Batts-Allen, A., \& Hancock, J. (2007). Self-compassion and reactions to unpleasant self-relevant events: The implications of treating oneself kindly. Journal of Personality and Social Psychology, 92, 887-904. https://doi. org/10.1037/0022-3514.92.5.887

Lilja, J. L., Frodi-Lundgren, A., Hanse, J. J., Josefsson, T., Lundh, L. G., Sköld, C., \& Broberg, A. G. (2011). Five Facets Mindfulness Questionnaire - reliability and factor structure: a Swedish version. Cognitive Behaviour Therapy, 40, 291-303. https://doi.org/10. 1080/16506073.2011.580367
Limebury, J., \& Shea, S. (2015). The role of compassion and 'Tough Love' in caring for and supporting the homeless: Experiences from 'Catching Lives' Canterbury, UK. Journal of Compassionate Health Care, 2, article 7. https://doi.org/10.1186/s40639015-0016-1

LoParo, D., Mack, S., Patterson, B., Negi, L., \& Kaslow, N. (2018). The efficacy of cognitively-based compassion training for African American suicide attempters. Mindfulness, 9, 1941-1954. https://doi.org/10.1007/ s12671-018-0940-1

Lovibond, P. F., \& Lovibond, S. H. (1995). The structure of negative emotional states: Comparison of the Depression Anxiety Stress Scales (DASS) with the Beck Depression and Anxiety Inventories. Behaviour Research and Therapy, 33, 335-343. https:// doi.org/10.1016/0005-7967(94)00075-U

Mahoney, C. T., Segal, D. L., \& Coolidge, F. L. (2015). Anxiety sensitivity, experiential avoidance, and mindfulness among younger and older adults: Age differences in risk factors for anxiety symptoms. International Journal of Aging and $\mathrm{Hu}$ man Development, 81, 217-240. https://doi.org/ 10.1177/0091415015621309

Mantzios, M. (2014). Exploring the relationship between worry and impulsivity in military recruits: the role of mindfulness and self-compassion as potential mediators. Stress and Health, 30, 397-404. https://doi.org/10.1002/smi.2617

Mantzios, M. (2020). Mental health first aid and exciting opportunities for peer-support networks within universities with prospects of influencing public health and treatment. Journal of Public Health, 28, 219-221. https://doi.org/10.1007/s10389-01901057-5

Mantzios, M., Cook, A., \& Egan, H. (2019a). Mental health first aid for students in the health professions: Exploring opportunities for experiential learning in higher education. Health Professions Education, 5, 281-282. https://doi.org/10.1016/j. hpe.2019.03.001

Mantzios, M., Cook, A., \& Egan, H. (2019b). Mental health first aid embedment within undergraduate psychology curriculums: An opportunity of applied experience for psychology students and for enhancing mental health care in higher education institutions. Higher Education Pedagogies, 4, 307-310. https://doi.org/10.1080/23752696.2019.1640631

Mantzios, M., \& Egan, H. (2017). On the role of selfcompassion and self-kindness in weight regulation and health behavior change. Frontiers in Psychology, 8, 229. https://doi.org/10.3389/fpsyg.2017.00229

Mantzios, M., \& Giannou, K. (2018). A real-world application of short mindfulness-based practices: a review and reflection of the literature and a practical proposition for an effortless mindful lifestyle. American Journal of Lifestyle Medicine, 13, 520-525. https://doi.org/10.1177/1559827618772036 
Mantzios, M., \& Wilson, J. (2013). Improving psychological wellbeing of military personnel by diminishing negative automatic thoughts and intolerance of uncertainty: The role of mindfulness training. Wessex Psychologist Bulletin, 8, 46.

Mantzios, M., \& Wilson, J. (2015). Exploring mindfulness and mindfulness with self-compassioncentered interventions to assist weight loss: Theoretical considerations and preliminary results of a randomized pilot study. Mindfulness, 6, 824-835. https://doi.org/10.1007/s12671-014-0325-z

Mantzios, M., Wilson, J., Linnell, M., \& Morris, P. (2014). The role of negative cognition, intolerance of uncertainty, mindfulness, and self-compassion in weight regulation among male army recruits. Mindfulness, 6, 545-552. https://doi.org/10.1007/ s12671-014-0286-2

McArthur, M., Mansfield, C., Matthew, S., Zaki, S., Brand, C., Andrews, J., \& Hazel, S. (2017). Resilience in veterinary students and the predictive role of mindfulness and self-compassion. Journal of Veterinary Medical Education, 44, 106-115. https://doi. org/10.3138/jvme.0116-027R1

McLaughlin, K. (2011). The public health impact of major depression: a call for interdisciplinary prevention efforts. Prevention Science, 12, 361-371. https:// doi.org/10.1007/s11121-011-0231-8

Meland, A., Ishimatsu, K., Pensgaard, A., Wagstaff, A., Fonne, V., Garde, A., \& Harris, A. (2015). Impact of mindfulness training on physiological measures of stress and objective measures of attention control in a military helicopter unit. The International Journal of Aviation Psychology, 25, 191-208. https:// doi.org/10.1080/10508414.2015.1162639

Mongrain, M., Chin, J., \& Shapira, L. (2010). Practicing compassion increases happiness and selfesteem. Journal of Happiness Studies, 12, 963-981. https://doi.org/10.1007/s10902-010-9239-1

Neff, K. (2003). The development and validation of a scale to measure self-compassion. Self and Identity, 2, 223-250. https://doi.org/10.1080/15298860 309027

Neff, K. D., \& Pommier, E. (2013). The relationship between self-compassion and other-focused concern among college undergraduates, community adults, and practicing meditators. Self and Identity, 12, 160176. https://doi.org/10.1080/15298868.2011.649546

Nery-Hurwit, M., Yun, J., \& Ebbeck, V. (2018). Examining the roles of self-compassion and resilience on health-related quality of life for individuals with multiple sclerosis. Disability and Health Journal, 11, 256-261. https://doi.org/10.1016/j.dhjo.2017.10.010

Pidgeon, A. M., \& Keye, M. (2014). Relationship between resilience, mindfulness, and psychological well-being in university students. International Journal of Liberal Arts and Social Science, 2, 27-32.

Rajgopal, T. (2010). Mental well-being at the workplace. Indian Journal of Occupational and Environmental
Medicine, 14, 63-65. https://doi.org/10.4103/00195278.75691

Roulston, A., Montgomery, L., Campbell, A., \& Davidson, G. (2017). Exploring the impact of mindfulness on mental wellbeing, stress and resilience of undergraduate social work students. Social Work Education, 37, 157-172. https://doi.org/10.1080/026 15479.2017.1388776

Ruiz-Casares, M., Guzder, J., Rousseau, C., \& Kirmayer, L. (2014). Cultural roots of well-being and resilience in child mental health. In A. Ben-Arieh, F. Casas, I. Frønes, \& J. Korbin (Eds.), Handbook of child well-being (pp. 2379-2407). Dordrecht: Springer.

Schaefer, K., Esposito-Smythers, C., \& Riskind, J. (2012). The role of impulsivity in the relationship between anxiety and suicidal ideation. Journal of Affective Disorders, 143, 95-101. https://doi. org/10.1016/j.jad.2012.05.034

Shrivastava, A., De Sousa, A., Sonavane, S., \& Shah, N. (2016). Resilience improves neurocognition and treatment outcomes in schizophrenia: a hypothesis. Open Journal of Psychiatry, 6, 173-187. https:// doi.org/10.4236/ojpsych.2016.62021

Smith, B., Tooley, E., Christopher, P., \& Kay, V. (2010). Resilience as the ability to bounce back from stress: A neglected personal resource? The Journal of Positive Psychology, 5, 166-176. https://doi.org/ $10.1080 / 17439760.2010 .482186$

Soysa, C. K., \&Wilcomb, C. J. (2015). Mindfulness, selfcompassion, self-efficacy, and gender as predictors of depression, anxiety, stress, and well-being. Mindfulness, 6, 217-226. https://doi.org/10.1007/ s12671-013-0247-1

Wamsler, C. (2018). Mind the gap: The role of mindfulness in adapting to increasing risk and climate change. Sustainability Science, 13, 1121-1135. https://doi.org/10.1007/s11625-017-0524-3

Wied, M., Oehmen, J., \& Welo, T. (2019). Conceptualizing resilience in engineering systems: an analysis of the literature. Systems Engineering, 23, 3-13. https://doi.org/10.1002/sys.21491

Yarnell, L. M., Stafford, R. E., Neff, K. D., Reilly, E. D., Knox, M. C., \& Mullarkey, M. (2015). Meta-analysis of gender differences in self-compassion. Self and Identity, 14, 499-520. https://doi.org/10.1080/ 15298868.2015 .1029966

Zessin, U., Dickhäuser, O., \& Garbade, S. (2015). The relationship between self-compassion and wellbeing: a meta-analysis. Applied Psychology: Health and Well-Being, 7, 340-364. https://doi.org/10.1111/ aphw.12051

Zhang, H., Watson-Singleton, N., Pollard, S., Pittman, D., Lamis, D., Fischer, N., Patterson, B., \& Kaslow, N. J. (2019). Self-criticism and depressive symptoms: Mediating role of self-compassion. OMEGA - Journal of Death and Dying, 80, 202-223. https://doi.org/10.1177/0030222817729609 